\title{
Evaluation of mid- and long-term impact of COVID-19 on male fertility through evaluating semen parameters
}

\author{
Bintao Hu ${ }^{1,2 \#}$, Kang Liu ${ }^{1,2 \#}$, Yajun Ruan ${ }^{1,2}$, Xian Wei ${ }^{1,2}$, Yue Wu ${ }^{1,2}$, Huan Feng ${ }^{1,2}, Z_{\text {Zhiyao Deng }}^{1,2}$, \\ Jihong Liu ${ }^{1,2}$, Tao Wang ${ }^{1,2}$ \\ ${ }^{1}$ Department of Urology, Tongji Hospital, Tongji Medical College, Huazhong University of Science and Technology, Wuhan, China; ${ }^{2}$ Institute of \\ Urology, Tongji Hospital, Tongji Medical College, Huazhong University of Science and Technology, Wuhan, China \\ Contributions: (I) Conception and design: B Hu, K Liu, J Liu, T Wang; (II) Administrative support: Y Ruan, X Wei, J Liu, T Wang; (III) Provision of \\ study materials or patients: B Hu, K Liu, Y Ruan, Y Wu, H Feng, Z Deng; (IV) Collection and assembly of data: X Wei, Y Wu, H Feng, Z Deng; (V) \\ Data analysis and interpretation: B Hu, K Liu, Y Ruan, J Liu, T Wang; (VI) Manuscript writing: All authors; (VII) Final approval of manuscript: All \\ authors. \\ \#These authors contributed equally to this work. \\ Correspondence to: Tao Wang. Department of Urology, Institute of Urology, Tongji Hospital, Tongji Medical College, Huazhong University of Science \\ and Technology, 1095 Jiefang Avenue, Qiaokou District, Wuhan 430030, China. Email: tjhwt@126.com.
}

Background: The coronavirus disease 2019 (COVID-19) has spread worldwide with alarming levels of spread and severity. The distribution of angiotensin converting enzyme 2 (ACE2) and transmembrane protease serine 2 (TMPRSS2) from bioinformatics evidence, the autopsy report for COVID-19 and the published study on sperm quality indicated COVID-19 could have a negative impact on male fertility. However, whether the negative impact of COVID-19 on male fertility is persistent remains unknown, which requires long-term follow-up investigation.

Methods: Semen samples were collected from 36 male COVID-19 patients with a median recovery time of 177.5 days and 45 control subjects. Then, analysis of sperm quality and alterations of total sperm number with recovery time were performed.

Results: There was no significant difference in semen parameters between male recovered patients and control subjects. And the comparisons of semen parameters between first follow-up and second follow-up revealed no significant difference. In addition, we explored the alterations of sperm count with recovery time. It showed that the group with recovery time of $\geq 120$ and $<150$ days had a significantly lower total sperm number than controls while the other two groups with recovery time of $\geq 150$ days displayed no significance with controls, and total sperm number showed a significant decline after a recovery time of 90 days and an improving trend after a recovery time of about 150 days.

Conclusions: The sperm quality of COVID-19 recovered patients improved after a recovery time of nearly half a year, while the total sperm number showed an improvement after a recovery time of about 150 days. COVID-19 patients should pay close attention to the quality of semen, and might be considered to be given medical interventions if necessary within about two months after recovery, in order to improve the fertility of male patients as soon as possible.

Keywords: Coronavirus disease 2019 (COVID-19); severe acute respiratory syndrome coronavirus 2 (SARSCoV-2); sperm quality; male fertility

Submitted Oct 17, 2021. Accepted for publication Jan 11, 2022.

doi: $10.21037 /$ tau-21-922

View this article at: https://dx.doi.org/10.21037/tau-21-922 


\section{Introduction}

In December 2019, a novel coronavirus-associated pneumonia was first reported, and then rapidly spread worldwide. The World Health Organization (WHO) later designated it as the coronavirus disease 2019 (COVID-19) in February 2020 (1). And the virus causing COVID-19 is currently named severe acute respiratory syndrome coronavirus 2 (SARS-CoV-2) due to its high sequence similarity ( $80 \%)$ with SARS-CoV (2). As of $11 \mathrm{March}$ 2020 , more than 118,000 cases were infected in 114 countries, and over 4 thousand people had lost their lives, therefore WHO announced the disease a pandemic as the alarming levels of spread and severity (3). Up to May 2021, there have been more than 100 million confirmed cases of COVID-19, including about 3 million deaths (4). During the pandemics, to constrain the worldwide outbreak of COVID-19, global researchers have made a lot of efforts in the viral pathogenesis, transmission route, disease prevention and management, etc. With the continuous progress of the pandemic, the impact of the COVID-19 on human reproduction has attracted more and more attention.

It has been reported that the SARS-CoV-2 genomic sequence is similar to the previous SARS-CoV (2), and both have identical receptor-binding domains (5). Therefore, SARS-CoV-2 has many similarities with SARS-CoV. For instance, they share the same receptor ACE2 for cell entry, while SARS-CoV-2 S protein has a higher affinity in the interaction with the human ACE2 receptor, which could explain the pandemic status of COVID-19 (6). And viral S protein then undergoes proteolytic priming and activation by the transmembrane serine protease (TMPRSS2) on the host cell membrane (7), which promotes the fusion of virus and cells and the entry into cells. ACE2 and TMPRSS2 are the two primary host molecules identified for the infectivity of SARS-CoV-2, although other possibly involved actors are under study $(8,9)$. Since ACE2 is expressed in the testes and seminal vesicles and TMPRSS2 could be detected in the prostate gland, testes and epididymis $(10,11)$, they are potential targets of SARS-CoV-2, suggesting COVID-19 may have an impact on male fertility.

Actually, similar to SARS-CoV (12), 19\% confirmed COVID-19 patients experienced scrotal discomfort (13) and some autopsy reports of COVID-19 patients showed that there was edema, inflammatory infiltrates and various degrees of spermatogenic cell reduction and injury in the testes $(14,15)$, which might indicate the possibility of developing orchitis in COVID-19 patients. Moreover, 4 of 12 COVID-19 recovered patients with 78.5 days of median time between semen collection and disease onset had low sperm motility and higher sperm DNA fraction percentages (16), one of the cases could display about $16 \%$ declines after COVID-19 infection in total mobile sperm count. Furthermore, COVID-19 patients with a mean time of 25.5 days between the end of symptoms and semen collection, who recovered from moderate infection, had significant impairment of sperm quality compared with a control group and men recovered from a mild infection, including total sperm number (about $95 \%$ declines compared with controls') and sperm concentration (17). Likewise, our previous follow-up research on COVID-19 recovered patients with 80 days of the median time between last positive pharyngeal swab test and semen collection showed a decline in sperm quality, including total sperm number (about 24\% declines compared with age-matched healthy controls'), sperm concentration, and total sperm motility (18). Taken together, the above studies indicate that male patients with COVID-19 do have some degree of decline in reproductive function.

It is reported that acute infections such as influenza viruses and pneumonia can have systemic effects on the body and have been found to affect semen quality as well. Decreased sperm motility and sperm count and changes in sperm morphology have been reported from 4 to 11 weeks after fever. There is also evidence that flu may damage the DNA integrity of sperm (19-21). However, there are no systematic studies of how long the damage lasts. As the mumps virus known to have similar damage to seminiferous tubules could cause the continuous reduction in semen parameters (22), whether the negative impact of COVID-19 on male fertility is persistent remains unknown, which requires long-term follow-up investigation. As it is shown that around $55 \%$ of male COVID-19 patients were reproductive-aged in a retrospective study involving 1,099 cases (23), long-term investigation on whether COVID-19 will permanently affect male fertility appears to be of great significance.

In this study, we conducted a further follow-up investigation on the first follow-up population and collected semen samples for semen analysis to assess the mid- and long-term impact of COVID on the quality of male semen.

We present the following article in accordance with the STROBE reporting checklist (available at https://tau. amegroups.com/article/view/10.21037/tau-21-922/rc). 


\section{Methods}

\section{Study design and participants}

To evaluate the mid- and long-term impact of COVID-19 on male fertility, we conducted a further follow-up investigation on the previous follow-up participants. To rule out the effect of preexisting andrological conditions on semen parameters as possible, men with other acute illnesses or severe chronic diseases, history of mumps infection, or semen volume less than $1.5 \mathrm{~mL}$ were excluded. Thirtysix COVID-19 recovered patients and 45 age-matched healthy men were recruited in this study from August 15 to September 17, 2020. Eighty-one semen samples were obtained from them after a recommended abstinence period of 3-7 days. All recovered patients were confirmed as SARS-CoV-2 positive in the previous follow-up study using real-time reverse transcriptase-polymerase chain reaction (RT-PCR) assay of pharyngeal swab specimens. Moreover, they had been in the recovery state in the previous followup, which referred to the condition with lessen symptoms and two continuous negative SARS-CoV-2 nucleic acid tests (time interval required for more than 24 hours). The last positive test time of tested subjects prior to getting lessened symptoms and two continuous negative tests or more (regarded as the beginning of recovery time) in this study was from January 25 to May 3, 2020. The diagnosis and classification of COVID-19 were determined according to the New Coronavirus Pneumonia Prevention and Control Program (7th ed.) published by the National Health Commission of China. Patients who displayed mild clinical symptoms and no radiological evidence of pneumonia were regarded as mild cases of COVID-19. By contrast, patients with fever, respiratory symptoms or other symptoms, and radiological manifestations of pneumonia were considered as moderate cases. Patients who met one of the following criteria were listed as severe cases of COVID-19: respiratory rate $\geq 30 / \mathrm{min}$; finger oxygen saturation at resting state $\leq 93 \%$; arterial partial pressure of oxygen $\left(\mathrm{PaO}_{2}\right)$ /fractional concentration of inspired oxygen $\left(\mathrm{FiO}_{2}\right) \leq 300 \mathrm{mmHg}$. The study was conducted in accordance with the Declaration of Helsinki (as revised in 2013). It was registered at ClinicalTrials.gov (identifier NCT04388631), and was approved by the Ethics Committee of Tongji Medical College (No. 2020-S073). All participants gave written informed consent.

\section{Data collection}

The recovered patients' demographic and clinical characteristics were obtained from medical records, while the controls' were recorded by inquiring about medical history at their hospital visit. The acquired information was curated with a standardized data collection form and double-checked by two researchers independently. All the semen samples were obtained by masturbation and ejaculation directly into noncytotoxic sterile containers after a recommended abstinence period of 3-7 days. Freshly collected semen was liquefied for $30-60 \mathrm{~min}$ at room temperature and processed within 1 hour of ejaculation for analysis of sperm characteristics according to the WHO laboratory manual for the examination and processing of human semen (5th edition) (24). Moreover, the andrology staffs were blinded to the samples that were being reported.

\section{Statistical analysis}

All statistical analysis was performed using SPSS statistical software version 25 (IBM). Continuous variables were presented as mean \pm standard deviation (SD) or median and interquartile ranges (IQR). Semen parameters were analyzed using Mann-Whitney $U$ test or independent $t$ test or paired $t$ test or Wilcoxon signed rank test, as appropriate. Statistical significance was defined as $\mathrm{P}$ values of $<0.05$.

\section{Results}

The study population consisted of 36 male recovered patients with a median recovery time of 177.5 days (IQR, 150.8-187.0) and a control group of 45 men without being affected by COVID-19 or preexisting infertility disease. The demographic and clinical characteristics of participants are shown in Table 1. Among COVID-19 recovered patients, $4(11.1 \%)$ with asymptomatic infection were regarded as mild type, 17 (47.2\%) were diagnosed as moderate COVID-19, the remaining patients (41.7\%) were classified into severe type. The recovered participants were $31.75 \pm 5.77$ years old, and the control group were $31.49 \pm 3.10$ years old (no statistical difference). In the acute infection of COVID-19, most of the patients developed fever $(83.3 \%)$, while cough and diarrhea were relatively less common. Of these recovered patients, two had a history of varicocele, the remaining and age-matched controls denied 
Table 1 Demographics, clinical characteristics of recovered COVID-19 patients and controls

\begin{tabular}{|c|c|c|}
\hline Characteristic & $\begin{array}{c}\text { Recovered } \\
\text { COVID-19 patients }\end{array}$ & $\begin{array}{l}\text { Age-matched } \\
\text { healthy controls }\end{array}$ \\
\hline Individuals, $\mathrm{n}$ & 36 & 45 \\
\hline Age, years & $31.75 \pm 5.77$ & $31.49 \pm 3.10$ \\
\hline Smoker, $\mathrm{n}$ & $5 / 36$ & - \\
\hline Drinker, $\mathrm{n}$ & $8 / 36$ & - \\
\hline $\begin{array}{l}\text { Pharyngeal swab } \\
\text { positive, } n\end{array}$ & $36 / 36$ & $0 / 45$ \\
\hline \multicolumn{3}{|l|}{ Symptoms, n } \\
\hline Fever & $30 / 36$ & $0 / 45$ \\
\hline Cough & $3 / 36$ & - \\
\hline Diarrhea & $7 / 36$ & - \\
\hline \multicolumn{3}{|c|}{ Classification of illness, $n$} \\
\hline Mild & $4 / 36$ & - \\
\hline Moderate & $17 / 36$ & - \\
\hline Severe & $15 / 36$ & - \\
\hline \multicolumn{3}{|l|}{ Past history, $\mathrm{n}$} \\
\hline Mumps & $0 / 36$ & $0 / 45$ \\
\hline Varicocele & $2 / 36$ & $0 / 45$ \\
\hline Recovery time, days & 177.5 (150.8-187.0) & - \\
\hline
\end{tabular}

Data presented as mean \pm standard deviation, unless specified otherwise. COVID-19, coronavirus disease 2019; n, number. the history of mumps and varicocele (Table 1).

Table 2 shows the comparisons of semen parameters between COVID-19 recovered patients and age-matched healthy men. There was no significant difference in semen parameters between them, including $\mathrm{PH}$, volume, sperm concentration, total sperm number, progressive motility and total motility.

In addition, based on the first follow-up data obtained early, we compared the second follow-up semen parameters with the first one in the same participants. It revealed no significant difference in semen volume, sperm concentration, total sperm number, progressive and total motility between first and second follow-up data (Table 3).

As previous investigation indicating that COVID-19 recovered patients had a significant decline of total sperm number after a recovery time of 90 days, with the aim to explore when total sperm number improved, we divided the second semen data of recovered patients into three groups according to the recovery time interval of 30 days: one with a recovery time of $\geq 120$ and $<150$ days, another one with a time of $\geq 150$ and $<180$ days, and the last one with a time of $\geq 180$ and $<210$ days. The three groups were compared with healthy controls separately. There was a significant difference between $\geq 120$ and $<150$ days group and controls, while the other two groups had no significance with controls. Together with the previous sperm count, we made a box-plot figure for analyzing the alteration of total sperm number with recovery time. It showed a significant

Table 2 Comparisons of semen parameters between recovered patients and controls

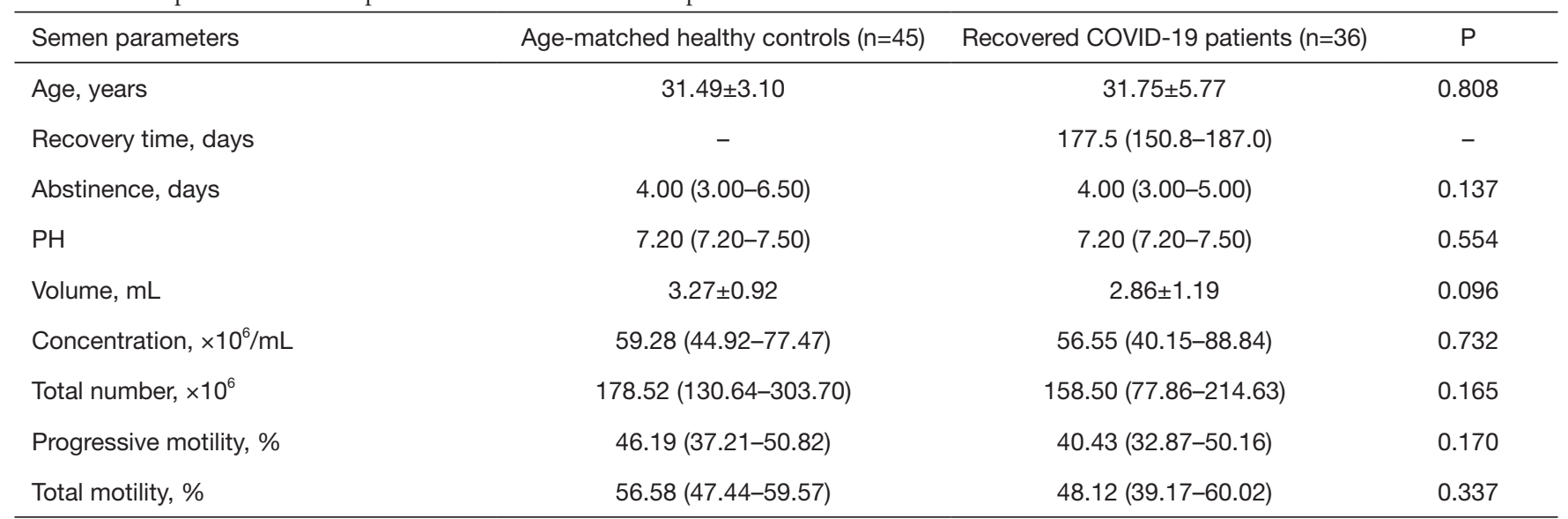

Data presented as mean \pm standard deviation or median (interquartile range). COVID-19, coronavirus disease 2019; $\mathrm{PH}$, hydrogen ion concentration; $n$, number; $P$ refers to the statistical significance of difference in semen parameters between age-matched healthy controls and recovered COVID-19 patients. 
Table 3 Comparisons of semen parameters between first and second follow-up $(n=31)$

\begin{tabular}{|c|c|c|c|}
\hline Semen parameters & First follow-up & Second follow-up & $\mathrm{P}$ \\
\hline Abstinence, days & $4.29 \pm 1.49$ & $4.19 \pm 1.14$ & 0.777 \\
\hline $\mathrm{PH}$ & $7.38 \pm 0.18$ & $7.34 \pm 0.22$ & 0.425 \\
\hline Volume, mL & $2.90(1.80-3.50)$ & $3.00(1.90-3.80)$ & 0.590 \\
\hline Concentration, $\times 10^{6} / \mathrm{mL}$ & $67.07 \pm 34.45$ & $60.65 \pm 26.96$ & 0.171 \\
\hline Total motility, \% & $50.91 \pm 12.76$ & $48.90 \pm 13.88$ & 0.427 \\
\hline Progressive motility, \% & $42.98 \pm 11.82$ & $40.20 \pm 12.33$ & 0.200 \\
\hline
\end{tabular}

Data presented as mean \pm standard deviation or median (interquartile range). $\mathrm{PH}$, hydrogen ion concentration; $\mathrm{n}$, number; $\mathrm{NA}$, not available; $\mathrm{P}$ refers to the statistical significance of difference in semen parameters between first follow-up and second follow-up.

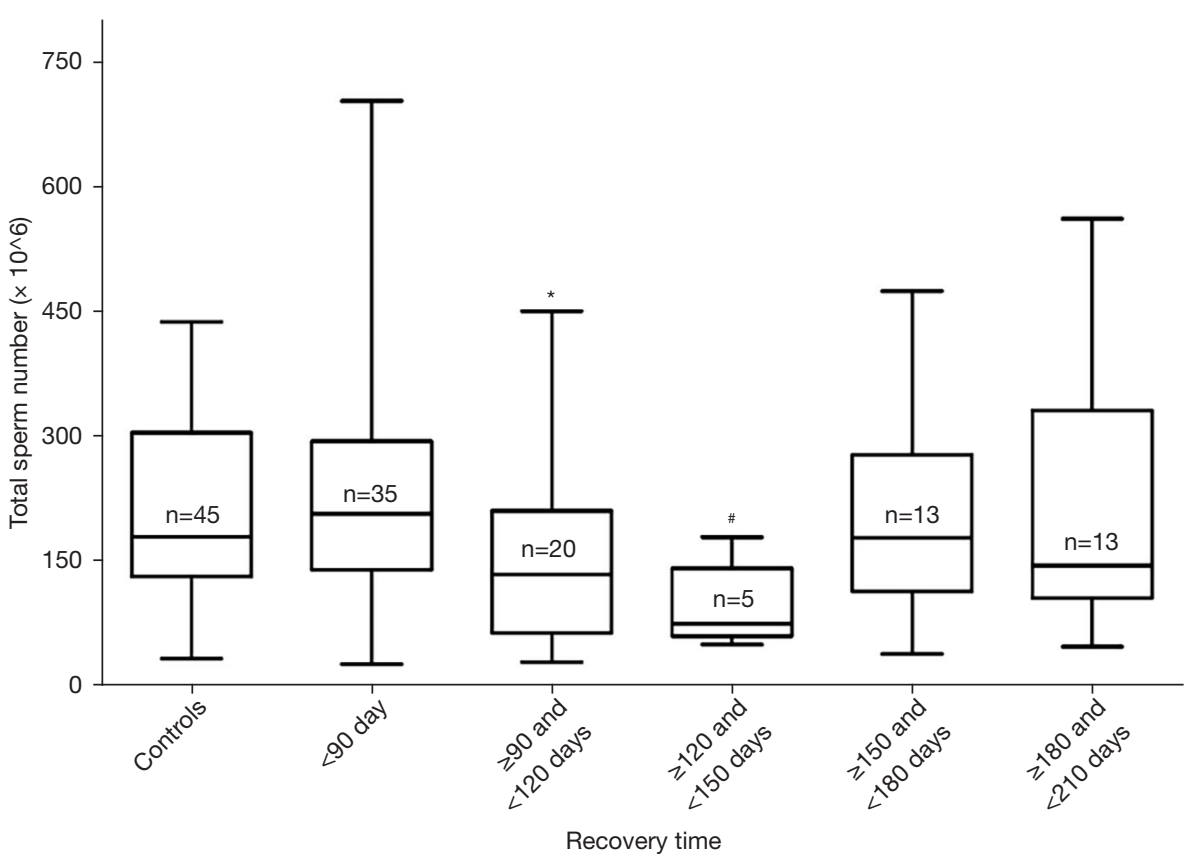

Figure 1 Alteration of total sperm number with recovery time. * , significant compared with $<90$ days group. ${ }^{*}$, significant compared with controls over the same period. $n$, number.

decline of total sperm number after a recovery time of 90 days and an improving trend of total sperm number after a recovery time of about 150 days (Figure 1). Likewise, we made a box-plot figure for analyzing the alteration of total sperm motility with recovery time. Total sperm motility in the recovery period of 120-210 days had no significance with controls. It might indicate that total sperm motility improved after a recovery time of 120 days (Figure 2).

\section{Discussion}

So far, more than 27 viruses are found in human semen (25), and several viruses have a negative impact on male reproductive function and spermatogenesis (26). For instance, mumps virus, human immunodeficiency virus and Zika virus all could induce orchitis and consequently lead to male infertility. Acute bacterial infections generally affect the epididymis and the accessory glands via ascending 


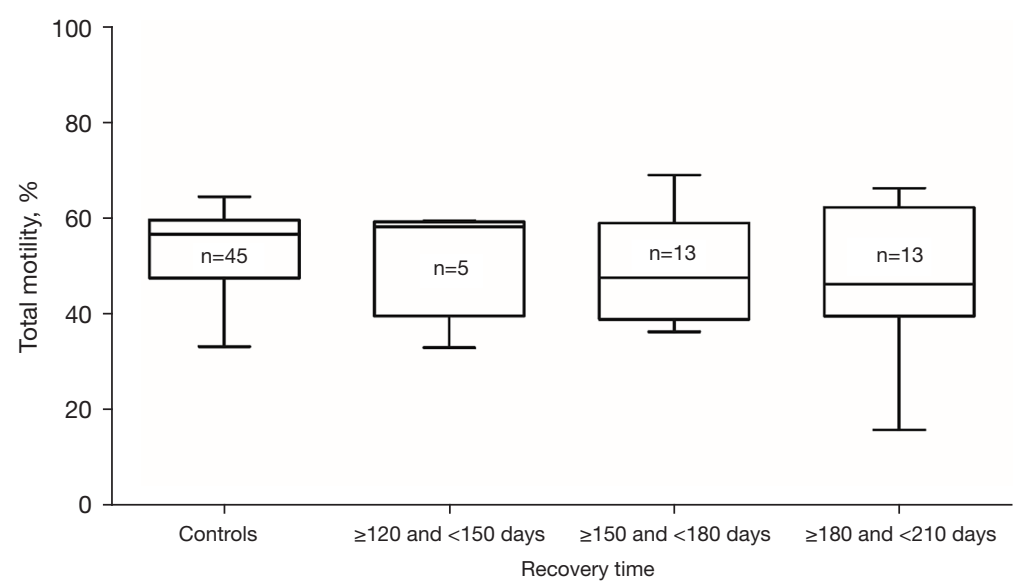

Figure 2 Alteration of total motility with recovery time. Total sperm motility in different recovery time period had no significance with Control. n, number.

the urogenital tract, whereas viral infection predominantly damages the testes through blood circulation (27). Acute viral infection could induce systemic response and affect sperm quality. The impaired sperm could be detected 4 to 11 weeks after fever. The possible mechanisms are speculated as follows: (I) fever causes increased testicular temperature and damages germ cell lines; (II) inducing orchitis and impairing the exocrine and endocrine function of testis (19-21).

Although the presence of SARS-CoV-2 in semen remains controversial (28), lots of evidence that SARS$\mathrm{CoV}-2$ may affect male fertility have been reported. For example, ACE2 and TMPRSS2 identified as the two primary molecules for the infectivity of SARS-CoV-2 are expressed in the male reproductive tissues (8-10). Moreover, a single-cell transcriptome sequencing study revealed that ACE2-positive cells in testis displayed a lower number of genes associated with spermatogenesis, mitochondria and reproduction (29). Furthermore, male COVID-19 patients showed lower gonadal function compared with age-matched control men, as a lower serum T: LH ratio was observed in patients (16). In addition, the autopsy report of COVID-19 patients showed various degrees of spermatogenic cell reduction and injury in the testes (14). However, the longterm effect of COVID-19 on male fertility currently stays unknown.

Here, we performed a further follow-up investigation for COVID-19 recovered patients with longer recovery time based on the previous research. No SARS-CoV-2 was detected in their semen samples in the previous research. Semen parameters were compared between male recovered patients and age-matched healthy men, and the alterations of sperm quality with recovery time were analyzed. Our study provides valuable clinical information on whether COVID-19 has a continuous negative impact on male fertility and has an indicative value for the andrology treatment of COVID-19 recovered patients.

The comparisons of sperm quality between male COVID-19 patients with a median recovery time of 177.5 days and age-matched healthy controls over the same period were evaluated. Our results revealed that recovered patients had no significant difference in semen parameters with controls after nearly half a year of recovery.

Similarly, Ma et al. (16) investigated 12 male COVID-19 patients whose median time of semen collection were 78.5 days after disease onset and assessed the sperm quality and sex hormone profiles. The results mainly demonstrated that some patients had low sperm motility and higher sperm DNA fraction percentages, and 119 male COVID-19 patients displayed lower gonadal function. Another similar research conducted by Holtmann et al. revealed that COVID-19 patients with a mean time of 25.5 days between the end of symptoms and semen collection had significant impairment of sperm quality compared with the control group (17). Different from our current research, both studies reflected the decline in sperm quality of male COVID-19 patients from the early recovery period (relative to the spermatogenesis cycle). Also, our previous investigation suggested that COVID-19 patients with a median recovery time of 80 days had significantly lower sperm quality than controls (18). Based on the above researches and Table 2, it suggested that sperm quality of 
COVID-19 patients improved after a recovery time of approximately six months.

In addition, we made a comparison of sperm quality between the first follow-up and second follow-up. Surprisingly, there was no significant difference in sperm parameters between them, and sperm quality of the second follow-up showed no sign of improving (30).

Vacuolization and detachment of Sertoli cells from the basal membrane and the reduction of Leydig cells and spermatogenic cells were observed in male COVID-19 patients $(14,15)$. Moreover, Sertoli cells and Leydig cells play a critical role in the homeostasis of seminiferous tubules and spermatogenesis $(31,32)$, and $39.1 \%$ of COVID-19 inpatients had oligozoospermia as research reported (33). The above indicated that COVID-19 could affect spermatogenesis. However, the alteration in Sertoli, Leydig and spermatogenic cells may lead to future impairment as modifications of the sperm count due to drama, injury and infection might be seen only after three months (17). The hypothesis is also supported by our previous follow-up study showing significantly lower total sperm number in $\geq 90$ days group compared with the $<90$ days group (18). Nevertheless, it remained unknown when the total sperm count improved.

Therefore, given that the impairment of total sperm number might be occurred in any day of recovery time and considering the limited sample size, we divided the sperm data of COVID-19 participants from two followup investigations into five groups at a follow-up interval of 30 days for analyzing alteration of total sperm number and total motility with recovery time. Total sperm motility had no significance with control after a recovery time of 120 days. Total sperm number of the group with recovery time of $\geq 120$ and $<150$ days was impaired, while the sperm count of groups with recovery time of $\geq 150$ and $<180$ days and $\geq 180$ and $<210$ days was improved. It showed a significant decline after a recovery time of 90 days and an improving trend of total sperm number after a recovery time of about 150 days. It could be inferred that spermatogenesis was impaired within recovery time of about two months, as a result of the spermatogenesis cycle of 90 days. Similarly, COVID-19 recovered patients at one or two months post-discharge presented persistent physical discomfort such as fatigue, dyspnea, chest pain and so on $(34,35)$. Thus spermatogenesis might be still affected two months after discharge, and the impairment of sperm quality showed an apparent delay effect in
120-150 days due to the spermatogenesis cycle and accumulative damage effect of the disease. Accordingly, COVID-19 patients might be suggested to be given medical interventions within about two months after recovery in order to improve the fertility of male patients as soon as possible. It was noteworthy that it might be cautiously to make such a conclusion as only five samples were in the 120-150 time period and the variation of total sperm number is relatively large. It needs a larger sample size to validate. In addition, Figure 1 showed less change in total sperm within 90 days versus significant declines later; it might be attributed to the accumulative effect of COVID-19 disease and delayed effect of spermatogenesis cycle, or it was owing to the different number distribution of patients with various disease severity.

To the best of our knowledge, our research is the longest follow-up study for evaluating semen parameters. It reveals the changes in sperm count of COVID-19 patients after recovery for the first time and has an indicative value for andrology treatment of recovered COVID-19 patients. Admittedly, there are certain limitations in this study. First, our sample size was relatively small, especially for exploring the alterations of semen parameters with time. A larger cohort study with different recovery time is required for confirmation and exploring the specific time at which sperm quality began to improve. Second, sperm analysis of participants performed before the infection of COVID-19 was not obtained, which cannot entirely exclude the possibility of preexisting infertility though they were not in the exclusion criteria. Finally, we did not conduct sex hormone analysis to evaluate testicular function comprehensively, just as it has spermatogenic and endocrine functions.

\section{Conclusions}

Although sperm quality of COVID-19 recovered patients was impaired during the early period, it improved after a recovery time of nearly half a year. In addition, we found that the total sperm number had an improvement after a recovery time of about 150 days. COVID-19 patients should pay close attention to the quality of semen, and might be considered to be given medical interventions if necessary within about two months after recovery, in order to improve fertility of male patients as soon as possible. It is noteworthy that the conclusion should be viewed with caution and needs a larger sample size to prove. 


\section{Acknowledgments}

We acknowledge the medical staff at andrological laboratory of Tongji Hospital for their assistance.

Funding: This work was supported by the Medical Youth Top Talent Program of Hubei Province (No. 2020LJRC009).

\section{Footnote}

Reporting Checklist: The authors have completed the STROBE reporting checklist. Available at https://tau. amegroups.com/article/view/10.21037/tau-21-922/rc

Data Sharing Statement: Available at https://tau.amegroups. com/article/view/10.21037/tau-21-922/dss

Peer Review File: Available at https://tau.amegroups.com/ article/view/10.21037/tau-21-922/prf

Conflicts of Interest: All authors have completed the ICMJE uniform disclosure form (available at https://tau.amegroups. com/article/view/10.21037/tau-21-922/coif). The authors have no conflicts of interest to declare.

Ethical Statement: The authors are accountable for all aspects of the work in ensuring that questions related to the accuracy or integrity of any part of the work are appropriately investigated and resolved. The study was conducted in accordance with the Declaration of Helsinki (as revised in 2013). It was registered at ClinicalTrials.gov (identifier NCT04388631), and was approved by the Ethics Committee of Tongji Medical College (No. 2020-S073). All participants gave written informed consent.

Open Access Statement: This is an Open Access article distributed in accordance with the Creative Commons Attribution-NonCommercial-NoDerivs 4.0 International License (CC BY-NC-ND 4.0), which permits the noncommercial replication and distribution of the article with the strict proviso that no changes or edits are made and the original work is properly cited (including links to both the formal publication through the relevant DOI and the license). See: https://creativecommons.org/licenses/by-nc-nd/4.0/.

\section{References}

1. WHO Director-General's Remarks at the Media Briefing on, 2019-NCoV on 11 February 2020. Available online: https://www.who.int/dg/speeches/detail/who-directorgeneral-s-remarks-at-the-media-briefing-on-2019-ncovon-11-february-2020. Accessed May 10, 2021.

2. Gralinski LE, Menachery VD. Return of the Coronavirus: 2019-nCoV. Viruses 2020;12:135.

3. WHO Director-General's opening remarks at the media briefing on COVID-19 - 11 March 2020. Available online: https://www.who.int/dg/speeches/detail/who-directorgeneral-s-opening-remarks-at-the-media-briefing-oncovid-19---11-march-2020. Accessed May 10, 2021.

4. WHO COVID-19 Dashboard, (2021). Available online: https://covid19.who.int/. Accessed May 10, 2021.

5. Lu R, Zhao X, Li J, et al. Genomic characterisation and epidemiology of 2019 novel coronavirus: implications for virus origins and receptor binding. Lancet 2020;395:565-74.

6. Gheblawi M, Wang K, Viveiros A, et al. AngiotensinConverting Enzyme 2: SARS-CoV-2 Receptor and Regulator of the Renin-Angiotensin System: Celebrating the 20th Anniversary of the Discovery of ACE2. Circ Res 2020;126:1456-74.

7. Hoffmann M, Kleine-Weber H, Schroeder S, et al. SARSCoV-2 Cell Entry Depends on ACE2 and TMPRSS2 and Is Blocked by a Clinically Proven Protease Inhibitor. Cell 2020;181:271-280.e8.

8. Malle L. A map of SARS-CoV-2 and host cell interactions. Nat Rev Immunol 2020;20:351.

9. Stanley KE, Thomas E, Leaver M, et al. Coronavirus disease-19 and fertility: viral host entry protein expression in male and female reproductive tissues. Fertil Steril 2020;114:33-43.

10. Liu X, Chen Y, Tang W, et al. Single-cell transcriptome analysis of the novel coronavirus (SARS-CoV-2) associated gene ACE2 expression in normal and non-obstructive azoospermia (NOA) human male testes. Sci China Life Sci 2020;63:1006-15.

11. Pascolo L, Zito G, Zupin L, et al. Renin Angiotensin System, COVID-19 and Male Fertility: Any Risk for Conceiving? Microorganisms 2020;8:1492.

12. Xu J, Qi L, Chi X, et al. Orchitis: a complication of severe acute respiratory syndrome (SARS). Biol Reprod 2006;74:410-6.

13. Pan F, Xiao X, Guo J, et al. No evidence of severe acute respiratory syndrome-coronavirus 2 in semen of males recovering from coronavirus disease 2019. Fertil Steril 2020;113:1135-9.

14. Bian XW; COVID-19 Pathology Team . Autopsy 
of COVID-19 patients in China. Natl Sci Rev 2020;7:1414-8.

15. Yang M, Chen S, Huang B, et al. Pathological Findings in the Testes of COVID-19 Patients: Clinical Implications. Eur Urol Focus 2020;6:1124-9.

16. Ma L, Xie W, Li D, et al. Evaluation of sex-related hormones and semen characteristics in reproductive-aged male COVID-19 patients. J Med Virol 2021;93:456-62.

17. Holtmann N, Edimiris P, Andree M, et al. Assessment of SARS-CoV-2 in human semen-a cohort study. Fertil Steril 2020;114:233-8.

18. Ruan Y, Hu B, Liu Z, et al. No detection of SARS-CoV-2 from urine, expressed prostatic secretions, and semen in 74 recovered COVID-19 male patients: A perspective and urogenital evaluation. Andrology 2021;9:99-106.

19. MacLEOD J. Effect of chickenpox and of pneumonia on semen quality. Fertil Steril 1951;2:523-33.

20. Evenson DP, Jost LK, Corzett M, et al. Characteristics of human sperm chromatin structure following an episode of influenza and high fever: a case study. J Androl 2000;21:739-46.

21. Sergerie M, Mieusset R, Croute F, et al. High risk of temporary alteration of semen parameters after recent acute febrile illness. Fertil Steril 2007;88:970.e1-7.

22. Masarani M, Wazait H, Dinneen M. Mumps orchitis. J R Soc Med 2006;99:573-5.

23. Guan WJ, Ni ZY, Hu Y, et al. Clinical Characteristics of Coronavirus Disease 2019 in China. N Engl J Med 2020;382:1708-20.

24. Cooper TG, Noonan E, von Eckardstein S, et al. World Health Organization reference values for human semen

Cite this article as: $\mathrm{Hu} \mathrm{B}, \mathrm{Liu} \mathrm{K}$, Ruan $\mathrm{Y}$, Wei $\mathrm{X}, \mathrm{Wu} \mathrm{Y}$, Feng H, Deng Z, Liu J, Wang T. Evaluation of mid- and longterm impact of COVID-19 on male fertility through evaluating semen parameters. Transl Androl Urol 2022;11(2):159-167. doi: 10.21037/tau-21-922 characteristics. Hum Reprod Update 2010;16:231-45.

25. Salam AP, Horby PW. The Breadth of Viruses in Human Semen. Emerg Infect Dis 2017;23:1922-4.

26. Liu W, Han R, Wu H, et al. Viral threat to male fertility. Andrologia 2018;50:e13140.

27. Bhushan S, Schuppe HC, Fijak M, et al. Testicular infection: microorganisms, clinical implications and hostpathogen interaction. J Reprod Immunol 2009;83:164-7.

28. Paoli D, Pallotti F, Turriziani O, et al. SARS-CoV-2 presence in seminal fluid: Myth or reality. Andrology 2021;9:23-6.

29. Wang Z, Xu X. scRNA-seq Profiling of Human Testes Reveals the Presence of the ACE2 Receptor, A Target for SARS-CoV-2 Infection in Spermatogonia, Leydig and Sertoli Cells. Cells 2020;9:920.

30. Durairajanayagam D. Lifestyle causes of male infertility. Arab J Urol 2018;16:10-20.

31. Griswold MD. The central role of Sertoli cells in spermatogenesis. Semin Cell Dev Biol 1998;9:411-6.

32. Zirkin BR, Papadopoulos V. Leydig cells: formation, function, and regulation. Biol Reprod 2018;99:101-11.

33. Li H, Xiao X, Zhang J, et al. Impaired spermatogenesis in COVID-19 patients. EClinicalMedicine 2020;28:100604.

34. D'Cruz RF, Waller MD, Perrin F, et al. Chest radiography is a poor predictor of respiratory symptoms and functional impairment in survivors of severe COVID-19 pneumonia. ERJ Open Res 2021;7:e00655-2020.

35. Carfi A, Bernabei R, Landi F, et al. Persistent Symptoms in Patients After Acute COVID-19. JAMA 2020;324:603-5. 